\title{
Raise Voltage Stability Limit of a Power System using Reactive Power Compensation Technique
}

\author{
V. Sundaravazhuthi, A.Alli Rani, M.Manoj Kumar
}

\begin{abstract}
In recent years, voltage stability problems have been increasing since power systems operate close to stability limits. The voltage stability problem of a power system is associated with a rapid voltage drop due to heavy system load and it occurs because of inadequate reactive power support at some critical bus. One of the serious consequences of the voltage stability is a system blackout, and this has received more attention in recent years. Accurate determination of stability limit and amount of reactive power injection to stabilize is important.This paper proposes to determine voltage stability margin of a critical bus and also provide amount of reactive power injection to the bus particularly during overload, a simple two bus equivalent model of the power system is used to determine the maximum apparent power for different power factors. Any required apparent power can directly obtained by correcting the reactive power at critical bus. Experimental results support our theoretical findings.
\end{abstract}

Keywords-Critical Voltage, Reactive Power, Voltage Stability, Harmonics.

\section{INTRODUCTION}

When power is supplied to a load through a transmission line keeping the sending end voltage constant, the receiving end voltage variations depends upon the reactive power and power factor of load. The voltage variation at a node is an indication of the unbalance between the reactive power generated and reactive power consumed by the load. The voltage stability problem can be analysed using the $\mathrm{P}-\mathrm{V}$ or $\mathrm{Q}-\mathrm{V}$ curve. A series of load flow simulations are usually required to generate the $\mathrm{PV}$ and $\mathrm{Q}-\mathrm{V}$ curve. However there is a critical load beyond which there is no load flow solution and thus the load flowmethod would not converge. The P-V curve and Q-V curves are plotted for a constant power factor and a family of such curves are usually required to study the voltage stability problem for various power factors.

Revised Manuscript Received on October 30, 2019.

V. Sundaravazhuthi*, Assistant Professor, Department of EEE, SASTRA University, Srinivasa Ramanujan Centre, Kumbakonam, TamilNadu, India (email: sundaravazhuthi@gmail.com)

Dr. A. Alli Rani, Professor/Associate Dean, SASTRA University,SrinivasaRamanujanCentre,Kumbakonam,TamilNadu,India

(email: adsrc@sastra.edu)

M. Manoj Kumar, Assistant Professor, Department of EEE, SASTRA University, Srinivasa Ramanujan Centre, Kumbakonam, TamilNadu, India (email: m21052014@gmail.com)

(C) The Authors. Published by Blue Eyes Intelligence Engineering and Sciences Publication (BEIESP). This is an open access article under the CC-BY-NC-ND license http://creativecommons.org/licenses/by-nc-nd/4.0/
* Correspondence Author

This paper describes a new method of assessing the voltage stability of a critical bus in a power system using maximum apparent power in P-Q plane. The maximum apparent power of a critical bus is obtained from a two bus equivalent of original system. The active, reactive power and critical voltage of the critical bus are then directly determined from the system.

\section{TWO BUS EQUIVALENT OF POWERSYSTEM}

With reference to fig.1, node one is a generated node with reference voltage v1 and node two is the load node with voltage v2. The two bus bars are interconnected through a short line. Assuming the interconnection to be lossless $(r=0)$ and voltage $\mathrm{v} 1$ constant then $\mathrm{v} 2$ is given by:

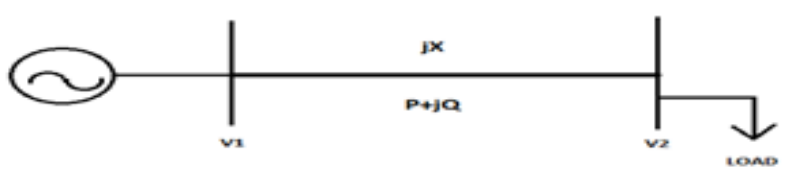

Fig.1, two bus equivalent model of power system

$\mathrm{V} 2=\mathrm{V} 1-\mathrm{IZ}$

$$
\begin{aligned}
& \mathrm{P}+\mathrm{JQ}=\mathrm{V} 1 \mathrm{I} \\
& \mathrm{V} 1 * \mathrm{I}=\mathrm{P}-\mathrm{JQ} \\
& \mathrm{I}=\mathrm{P}-\mathrm{JQ} / \mathrm{V} 1 *
\end{aligned}
$$

$\mathrm{V} 1 *=\mathrm{V} 1$,as $\mathrm{v} 1$ is the reference voltage

$$
\begin{aligned}
& \mathrm{V} 2=\mathrm{V} 1-\mathrm{IZ} \\
& \mathrm{V} 2=\mathrm{V} 1-\mathrm{j}(\mathrm{P}-\mathrm{JQ} / \mathrm{V} 1) \mathrm{X} \\
& \mathrm{V} 2=(\mathrm{V} 1-(\mathrm{Q} / \mathrm{V} 1 \mathrm{X}))-J P / \mathrm{V} 1 \mathrm{X}
\end{aligned}
$$

from the above it is clear that the load voltage v2 is not affected much due to real component of load ' $p$ ' and $v 2$ is more affected due to reactive component of load.

$$
\text { i.e } \quad \mathrm{V} 2=\mathrm{V} 1-\mathrm{Q} / \mathrm{V} 1 \mathrm{X}
$$

in order to keep the receiving end voltage v2 fixed for a particular sending end voltage $\mathrm{v} 1$, the variable quantity ' $Q$ ' must be locally adjusted to keep this quantity fixed. The local generation of reactive power can be obtained by connecting shunt capacitors.

\section{THEVENIN EQUIVALENT CIRCUIT OF A CRITICAL BUS}

Two bus equivalent of a power system can be obtained using thevenins theorem. Thevenin equivalent voltage can be obtained from load flow solution of a power system by considering all the loads except the load on critical bus.

Thevenins equivalent impedance (zth) can be obtained from kth diagonal element of $\mathrm{z}$-matrix and the load on the kth bus. 


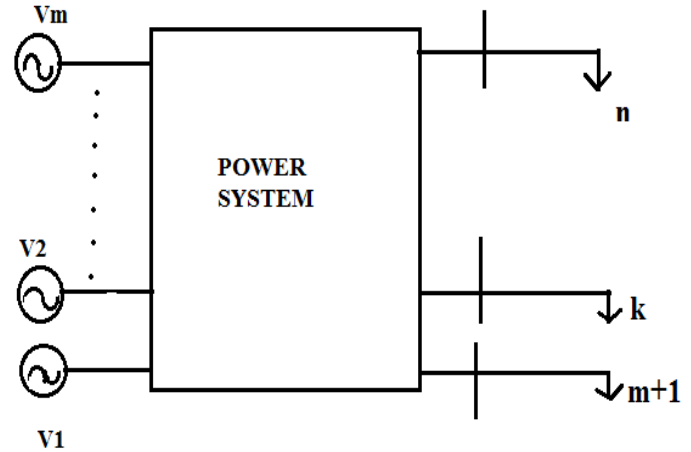

fig.2, block diagram of general power system

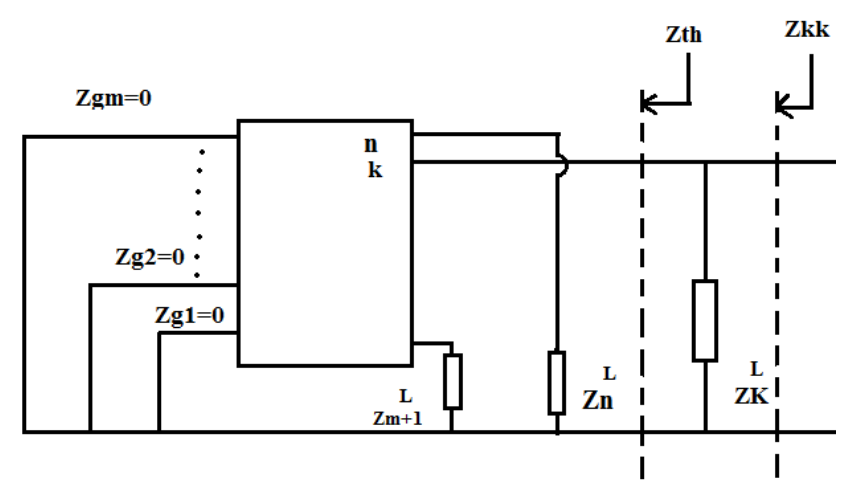

Fig.3, block diagram representing impedances of power system

The internal generator voltage Eg found in generators to adjust the terminal voltage in order to maintain it constant. Thus with with zero impedance in generating side thevenin circuit is made only considering impedance on load side.

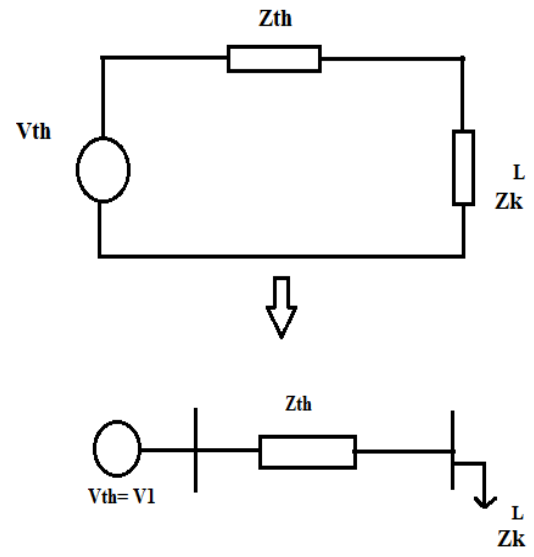

Fig.4, thevenin equivalent circuit for critical bus

On each load bus;

$\mathrm{ZiL}=|\mathrm{Vi}| 2 / \mathrm{Pi}-\mathrm{jQi}$

$\mathrm{ZKK}=\mathrm{Zth} \| \mathrm{ZK} 2$

$\mathrm{Zth}=\mathrm{ZKK} \times \mathrm{Zk} 2 / \mathrm{Zkk}-\mathrm{Zk} 2$

$\mathrm{Vth}=(1+\mathrm{Zth} / \mathrm{Zk} 2) \mathrm{Vk}$

Where, Vk is the voltage at bus $\mathrm{k}$ obtained from the load flow solution when all loads in the system are considered.

\section{RELATION BETWEEN APPARENT POWER AND VOLTAGE}

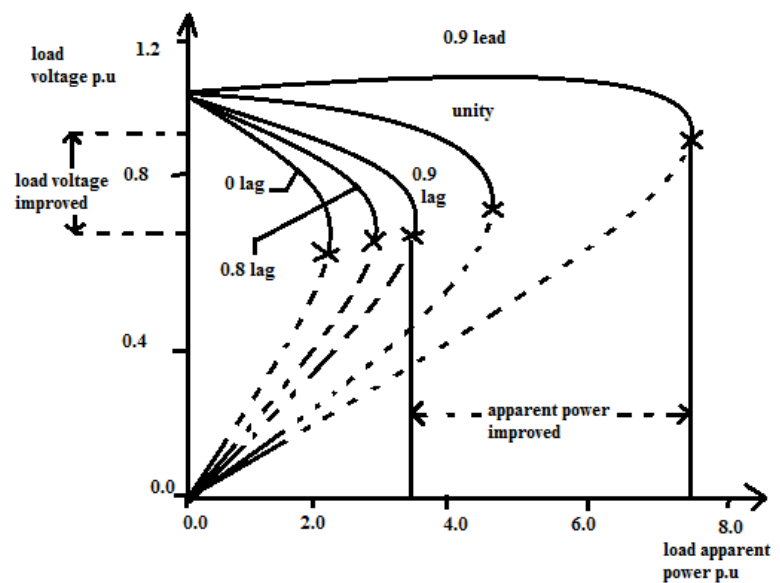

Fig.5, graph plotted between apparent power and load voltage for different power factors.

From fig.1, considering transmission line with impedance $\mathrm{Z}=\mathrm{R}+\mathrm{jQ}$ with $\mathrm{v} 1$ voltage constant as that corresponding bus is considered as swing bus. Now relation between receiving end power and load power $\mathrm{S}=\mathrm{P}+\mathrm{jQ}$ can be written as:

$\mathrm{V} 1 \wedge 2=\mathrm{V} 2 \wedge 2+2 *(\mathrm{RP}+\mathrm{XQ})+(\mathrm{R} \wedge 2+\mathrm{X} \wedge 2) *\left(\left(\mathrm{P}^{\wedge} 2+\mathrm{Q} / 2\right) / \mathrm{V} 2 \wedge 2\right)$

Assuming $\mathrm{V} 2 \wedge 2=\mathrm{x}$; we get a quadratic equation and solving it gives two solutions:

Where $\mathrm{a}=1$

$\mathrm{b}=2(\mathrm{RP}+\mathrm{XQ})-\mathrm{V} 1 \wedge 2$

$\mathrm{C}=\left(\mathrm{R} \wedge 2+\mathrm{X}^{\wedge} 2\right) *(\mathrm{P} \wedge 2+\mathrm{Q} \wedge 2)$

$\mathrm{d}=\mathrm{V} 1 \wedge 4+4\left[2 \mathrm{PQRX}-\mathrm{V} 1 \wedge 2^{*}(\mathrm{RP}+\mathrm{XQ})-\mathrm{R}^{\wedge} 2 \mathrm{Q}^{\wedge} 2-\mathrm{X}^{\wedge} 2 \mathrm{P} \wedge 2\right]$

equating $\mathrm{d}=0$ and solving quadratic equation we get;

$\mathrm{Sm}=(\mathrm{V} 1 \wedge 2[\mathrm{Z}-(\mathrm{R} \cos \phi+\mathrm{X} \sin \phi)]) / 2 *[\mathrm{R} \sin \phi+\mathrm{X} \cos \phi] \wedge 2$

$\mathrm{Vcr}=[(\mathrm{V} 1 \wedge 2-2 \operatorname{Sm}(\mathrm{R} \cos \phi+\mathrm{X} \sin \phi)) / 2] \wedge(1 / 2)$

$\mathrm{Vcr}=[(\mathrm{V} 1 \wedge 2-2 \mathrm{QmX}) / 2]^{\wedge}(1 / 2)$

Subistuiting angle $=90$ in critical voltage equation we get the relation between reavtive power and voltage stability limit of a critical bus.

\section{MAXIMUM APPARENT POWER IN P-Q PLANE}

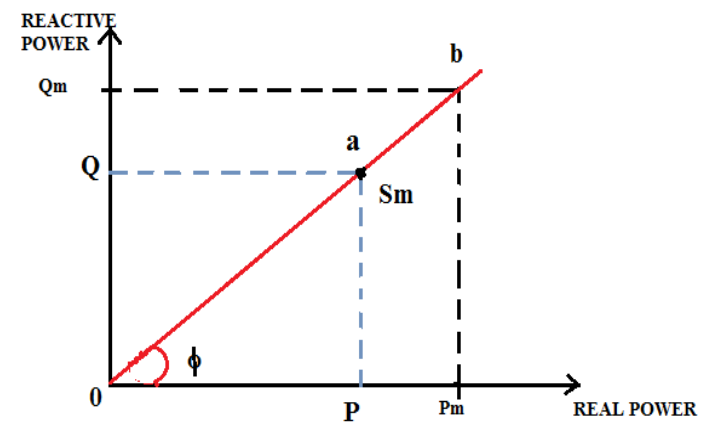

Fig.6, graphicalrepresentation of stability limit i.e., maximum apparent power of critical bus. 
We can predetermine the stability margin of critical bus at different power factors $(\Phi)$ and the power factor of a critical bus is desired by load on it as shown in fig.5.

Let us consider the load on a critical bus is $\mathrm{P}+\mathrm{jQ}$

$\operatorname{Cos} \phi=\operatorname{Cos}[\tan -1(\mathrm{Q} / \mathrm{P})]$

And then,

$\mathrm{Sm}=(\mathrm{V} 1 \wedge 2[\mathrm{Z}-(\mathrm{R} \cos \phi+\mathrm{X} \sin \phi)]) / 2 *[\mathrm{R} \sin \phi+\mathrm{X} \cos \phi] \wedge 2$

For a given power factor angle $\mathrm{Q}$ maximum real power can be obtained by setting $\mathrm{O}=0$ and maximum reactive power can be obtained by setting $\mathrm{O}=90$

$\mathrm{PM}=\mathrm{V} 1 \wedge 2(\mathrm{Z}-\mathrm{R}) / \mathrm{ZX} \wedge 2$

$\mathrm{QM}=\mathrm{V} 1 \wedge 2(\mathrm{Z}-\mathrm{X}) / \mathrm{ZR} \wedge 2$

For a particular power factor we predetermine Sm (oa) which is the maximum apparent power or stability margin of the critical bus. From the graph it can be understood that if the apparent power of load lieswithin line oa then system is stable and if lies between point $a$ and $b$ then it is unstable.

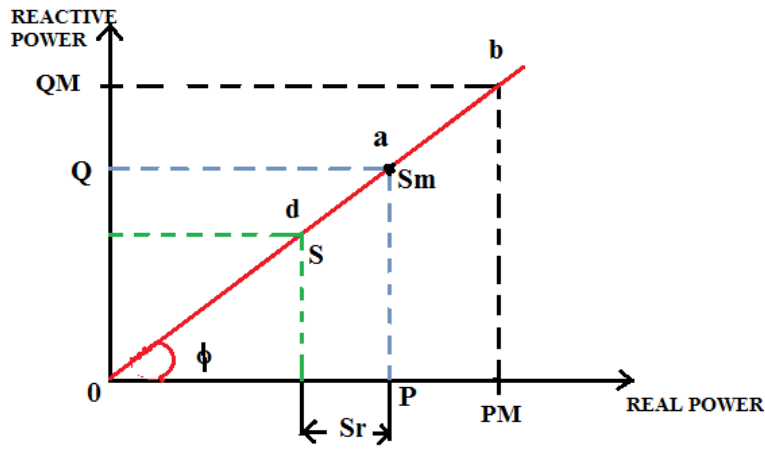

Fig.7, graphical representation of $\mathrm{S}<\mathrm{Sm}$

\section{A. CASE-I:}

The load apparent power s= sqrt. p2+q2 is less compared with $\mathrm{Sm}$, the voltage stability is maintained at the critical bus $\mathrm{k}$ and space (da) is the reserve capacity of apparent power at critical bus which is represented by $\mathrm{Sr}$ in fig.6.The real power and reactive power of that bus can be obtained using formula;

$\mathrm{Pr}=\mathrm{SrCosO}$

$\mathrm{Qr}=\mathrm{SrSinO}$

This excess reactive power can be supplied to any bus whịich in unstable.

B. CASE- II:

If the load apparent power $S$ located between a and $b$ then the load is unstable and this state can be overcome by adjusting the reactive power at the bus $\mathrm{k}$ by connecting a suitable compensating component which improves the power factor by supplying reactive power. The value of compensating component to be used is determined by the difference between (Qm-Q) as shown in fig.7.

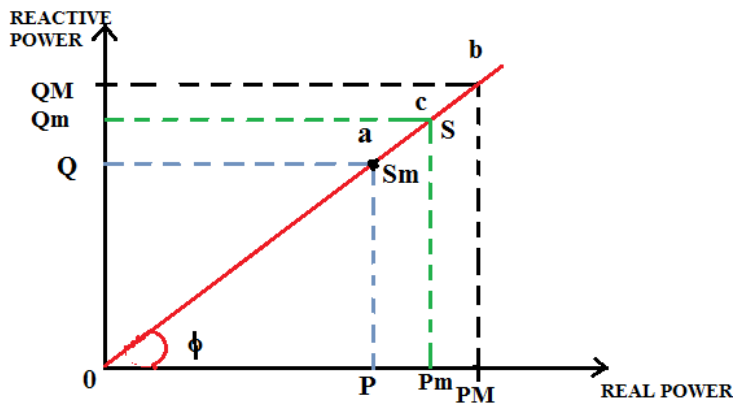

Fig.8, graphical representation of unstable critical bus
The adjusting reactive power can bring the operating point within valid portion of oSm.

\section{METHOD FOR STABLIZING UNSTABLE SYSTEM USING REACTIVE POWER COMPENSATION}

A. CASE-I:

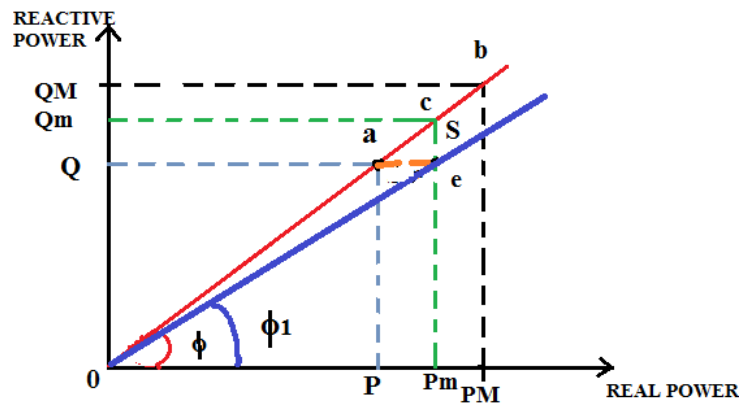

Fig.9, graphical representation of reactive power compensation method by power factor improvement.

fig.8, point (a) is the stability margin of critical bus but actually it is beyond this at point (c). Let the differenceQm$\mathrm{Q}=\mathrm{Q}, \mathrm{i} \Delta$ the amount of reactive power to be compensated and this determines the compensating component to be usedref[4]. The load at point (c) be $\mathrm{Pm}+\mathrm{jQm}$ which is unstable. So, to make the system stable we vary the reactive power only using suitable compensator which gives a new power factor $\mathrm{O} 1$ which can obtain as follows:

At point (C) shown in fig.8

Load $=P m+j(Q m-\triangle Q)$

Which can be written as; load $=P m+j Q$, this forms a new apparent power at point (e). As power factor is improved the maximum apparent power is varied which is different from previous one at point (a). Thus now load is at stable limit and new power factor can be obtained as follows:

$\operatorname{Cos} \phi 1=\operatorname{Cos}[\tan -1(\mathrm{Q} / \mathrm{Pm})]$, which is indicated by blue line in the fig.8.

\section{CASE-II}

In the fig.9 a purple line indicates the load apparent power. This is a case in which after compensation if operating point doesn't come under stable limit then from that point line is drawn parallel to real axis to measure reactive power say Q' , which is compared with Q and the same above procedure as in case $\mathrm{i}$ is repeated until the operating point comes under stable limit.

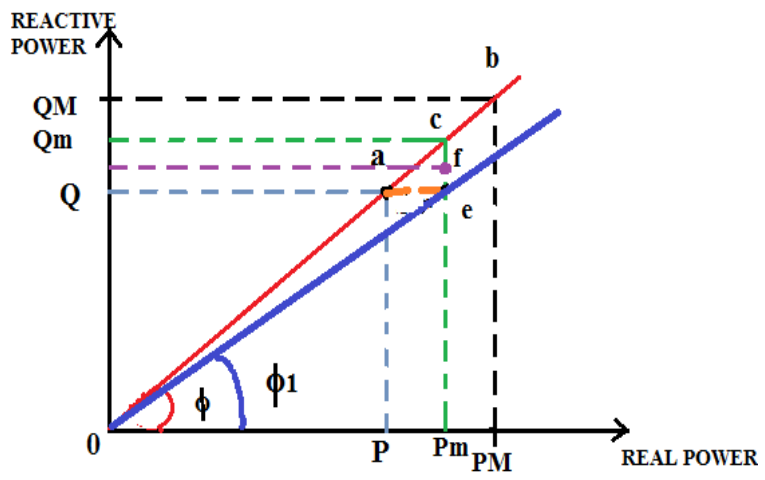

Fig.10, graphical representation of compensation method 


\section{CONCLUSION}

In this paper, the stability limit of any load in n-bus system can be improved without change of real power demand. Since power factor plays a role to improve the stability limit, the regulation and voltage drop of transmission line will be reduced by the method proposed in this paper. The reactive power cited is allowed from each generator is limited and harmonics are arrested. This method provides accurate rating of compensating device by optimisation i.e. this proves to be superior than any other method. And we have mat-lab program to calculate in short time. The result obtained was similar to the manual calculation.

\section{REFERENCES}

1. Amin Ibsais, VenkataramanaAjjarapu, "Voltage stability- limited interchange flow", in ELSEVIER trans.

2. S. QUINTEIA, student member IEEE, "improved branch based voltage stability proximity indices" in IEEE proceedings- 2002

3. Thomas j. Overbye, member IEEE, "Q-V curve interpretations of energy measures for voltage security" in IEEE trans. And power system- 1994.

4. C.L. WADHWA "power system ".

5. ANDERSON "a course of electric power system" 